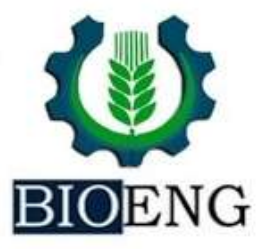

\section{QUALIDADE FISIOLÓGICA DE SEMENTES DE FEIJÃO SUBMETIDAS A ÁGUAS RESIDUÁRIAS EM LABORATÓRIO}

\author{
J. M. de Souza*, L. D. da Silva, L. R. Pereira, E. F. dos Reis, \\ G. de O. Garcia
}

Article history: Received 11 May 2015; Received in revised form 13 June 2015; Accepted 17 June 2015; Available online 30 June 2015.

\title{
RESUMO
}

Objetivou-se nesse trabalho avaliar a influência de águas residuárias na germinação e vigor de sementes de feijão cv. Serrano em laboratório. O delineamento experimental foi o inteiramente casualizado com quatro repetições de 25 sementes e seis tratamentos: sementes sem embebição, sementes embebidas em água por $1 \mathrm{~h}$, sementes embebidas em água residuária da suinocultura por $1 \mathrm{e} 2 \mathrm{~h}$, sementes embebidas água residuária de soro de leite (10\%) por 1 e 2 h. Avaliou-se: biometria das sementes, germinação, primeira contagem, índice de velocidade de germinação, tempo médio e frequência relativa de germinação, comprimento da parte aérea e radicular, massa de matéria fresca e seca da parte aérea e de raiz. As águas de soro de leite $(10 \%)$ e suinocultura proporcionaram uma melhoria no índice de velocidade de germinação. O soro de leite (10\%) proporcionou maior comprimento de raiz, e parte aérea e massa de matéria fresca de raiz quando utilizado por 1 e $2 \mathrm{~h}$, respectivamente. As águas residuárias não influenciaram a qualidade fisiológica das sementes, se tornando alternativas para o reúso, em germinação de sementes de feijão cv. Serrano.

Palavras-chave: Phaseolus vulgaris L., efluentes, reuso, vigor, germinação.

\section{PHYSIOLOGICAL QUALITY OF SEEDS OF BEANS SUBMITTED THE WASTEWATER IN A LABORATORY}

\begin{abstract}
The objective was to evaluate the influence of wastewater on the germination and vigor of bean seeds cv. Serrano in laboratory. The experimental design was completely randomized with four replications of 25 seeds and six treatments: seeds without soaking, seeds soaked in water for $1 \mathrm{~h}$, seeds soaked in swine wastewater for 1 and $2 \mathrm{~h}$, seeds soaked in cheese wastewater whey (10\%) for 1 to $2 \mathrm{~h}$. Were evaluated: biometrics seeds, germination, first count, germination speed index, average time and relative frequency of germination, length of root and shoot, fresh weight and dry shoot and root. The whey water (10\%) and pig farming provided an improvement in germination speed index. The whey water $(10 \%)$ provided greater root length, and shoot and fresh weight of the root when used for 1 and $2 \mathrm{~h}$, respectively. The wastewater did not affect the physiological quality of seeds, making alternatives for reuse in bean seed germination cv. Serrano.
\end{abstract}

Keywords: Phaseolus vulgaris L., effluent reuse, vigor, germination. 


\section{INTRODUÇÃO}

O feijão comum (Phaseolus vulgaris L.) ocupa lugar de destaque na agricultura brasileira, sendo caracterizado como forte produto no mercado interno, com grãos que representam uma importante fonte de proteínas e minerais na dieta da população, além de possuir notória importância socioeconômica (CARVALHO et al., 2014).

As sementes de feijão são uma via para a propagação e implantação de lavouras. Essas são colhidas, selecionadas e armazenadas para a semeadura no ano seguinte. Para a análise da qualidade de sementes há necessidade de complementar as informações fornecidas pelo teste de germinação com testes de vigor, os quais possibilitam selecionar os melhores lotes para comercialização (DIAS et al., 2006).

Nos testes de vigor baseados no desempenho ou características de plântulas, incluem-se os de primeira contagem e velocidade de germinação, comprimento de plântulas ou de suas partes constituintes (raiz primária, hipocótilo e/ou epicótilo), massa de matéria seca de plântulas e classificação do vigor (NAKAGAWA, 1994; MARCOS FILHO, 2005).

A busca de conhecimentos sobre as condições ótimas para a germinação das sementes e que dê ênfase aos efeitos de tratamentos alternativos e mais sustentáveis, já que segundo Rebouças et al. (2010) a busca de fontes alternativas mais eficientes de recursos hídricos, como a utilização de águas residuárias na

\section{MATERIAL E MÉTODOS}

Foram utilizadas sementes de feijão cv. Serrano, oriundas do mercado consumidor, as quais foram desinfetadas por imersão em solução de hipoclorito de sódio a $2 \%$, por dois minutos, seguida de lavagem em água corrente.

$\mathrm{O}$ delineamento experimental foi o inteiramente casualizado com quatro agricultura é uma tendência mundial devido a diminuindo gradativamente da qualidade da água. Como isso o reúso de desejos se torna importante, para que os recursos disponíveis e ao alcance dos agricultores possam desempenhar um papel fundamental dentro da pesquisa científica, pois fornecem informações sobre $o$ efeito dos mesmos no comportamento das espécies de sementes estudadas (BARBOSA et al., 2013).

O reúso agrícola é uma prática alternativa que fornece matéria orgânica, nutriente e água, possibilitando assegurar e incrementar a produção agrícola durante as estiagens prolongadas, em especial ao nível da agricultura familiar, contribuindo para a fixação do homem no campo (MENESES et al., 2014). Devido às agressões constantes ao meio ambiente, pesquisas têm sido direcionadas visando minimizar esse avanço na quantidade de desejos lançados nos recurso hídricos. Dentre as preocupações encontram-se os dejetos de laticínios, de suínos e da piscicultura, que possuem uma grande quantidade de nutrientes minerais dissolvidos, e que são desperdiçados quando suas águas são eliminados ou lançados em mananciais hídricos segundo Silva et al. (2014), podendo ser uma alternativa na germinação de sementes.

Diante das poucas informações sobre a embebição de sementes de feijão em águas residuárias, objetivou-se avaliar a influência de águas residuárias na germinação e vigor de sementes de feijão.

repetições de 25 sementes e seis tratamentos (T1 - sementes sem embebição (testemunha), T2 - sementes embebidas em água por $1 \mathrm{~h}, \mathrm{~T} 3$ - sementes embebidas em água residuária da suinocultura por $1 \mathrm{~h}, \mathrm{~T} 4$ - sementes embebidas em soro de leite $(10 \%)$ por $1 \mathrm{~h}, \mathrm{~T} 5$ - sementes embebidas em água residuária da suinocultura por $2 \mathrm{~h}$ 
e T6 - sementes embebidas em soro de leite $(10 \%)$ por $2 \mathrm{~h}$.
As características físico-químicas das águas residuárias se encontram descritas na Tabela 1.

Tabela 1. Composição físico-química das águas residuárias utilizadas.

\begin{tabular}{ccc}
\hline Parâmetros & Suinocultura & Soro de leite $\mathbf{( 1 0 \%})$ \\
\hline $\mathrm{C} . \mathrm{E}$ & $0,21\left(\mathrm{dS} \mathrm{m}^{-1}\right)$ & $\left.0,01(\mathrm{dS} \mathrm{m})^{-1}\right)$ \\
$\mathrm{pH}$ & 6,9 & 6,4 \\
$\mathrm{Na}$ & $29,21\left(\mathrm{meq} \mathrm{L}^{-1}\right)$ & $0,8\left(\mathrm{meq} \mathrm{L}^{-1}\right)$ \\
$\mathrm{P}$ & $2,84\left(\mathrm{mg} \mathrm{L}^{-1}\right)$ & $25,06\left(\mathrm{mg} \mathrm{L}^{-1}\right)$ \\
$\mathrm{K}$ & $9,9\left(\mathrm{mg} \mathrm{L}^{-1}\right)$ & $160\left(\mathrm{mg} \mathrm{L}^{-1}\right)$ \\
$\mathrm{Ca}$ & $0,26\left(\mathrm{meq} \mathrm{L}^{-1}\right)$ & $2,71\left(\mathrm{meq} \mathrm{L}^{-1}\right)$ \\
$\mathrm{Mg}$ & $0,13\left(\mathrm{meq} \mathrm{L}^{-1}\right)$ & $0,66\left(\mathrm{meq} \mathrm{L}^{-1}\right)$ \\
R.A.S.* & 66,15 & 0,62 \\
$\mathrm{Fe}$ & $0,33\left(\mathrm{mg} \mathrm{L}^{-1}\right)$ & $0,07\left(\mathrm{mg} \mathrm{L}^{-1}\right)$ \\
$\mathrm{B}$ & $0,14\left(\mathrm{mg} \mathrm{L}^{-1}\right)$ & $0,5\left(\mathrm{mg} \mathrm{L}^{-1}\right)$ \\
Mn & $0,04\left(\mathrm{mg} \mathrm{L}^{-1}\right)$ & $0,04\left(\mathrm{mg} \mathrm{L}^{-1}\right)$ \\
$\mathrm{O}_{2}$ dissolvido & $2,3(\%)$ & $4,7(\%)$ \\
\hline
\end{tabular}

*Relação de adsorção de sódio

As avaliações feitas nas sementes foram $o$ grau de umidade (\%) determinado pelo método da estufa (105 \pm $3{ }^{\circ} \mathrm{C}$ por $24 \mathrm{~h}$ ), e os resultados expressos em porcentagem (BRASIL, 2009). A biometria das sementes foi obtida com o auxílio de régua graduada, no qual foi medido o comprimento, a largura e a espessura das sementes, em milímetros e peso de 1000 sementes (BRASIL, 2009).

O teste de germinação, adaptado das Regras para Análise de Sementes (BRASIL, 2009) foi conduzido com quatro subamostras de 25 sementes para cada repetição/tratamento, distribuídas sobre papel germitest. Os tratamentos T1 e T2 foram umedecidos com água deionizada e para os demais tratamentos utilizou-se suas respectivas águas residuárias até o final do experimento, na proporção de duas vezes e meia a massa do papel germitest seco. As avaliações foram realizadas após quatro e nove dias da implantação do teste, computando se a porcentagem de plântulas normais (BRASIL, 2009) e os resultados expressos em porcentagem.

A primeira contagem (\%) foi realizada conjuntamente com o teste de germinação, computando-se a porcentagem de plântulas normais no quarto dia após a instalação do teste. Já o índice de velocidade de germinação foi determinado conforme Nakagawa (1994), sendo a contagem feita diariamente até o nono dia. O tempo médio de germinação (dias) e a frequência relativa de germinação (\%) foram calculados com os dados diários de germinação, de acordo com Labouriau (1983).

O comprimento da parte aérea e da raiz foi medido após nove dias da germinação, com o auxílio de régua milimetrada do nível da gema apical até o colo, com os resultados expressos em centímetros $(\mathrm{cm})$. O comprimento da raiz foi obtido pela medida tomada entre o colo da planta e a ponta da maior raiz em centímetros.

A massa de matéria fresca e seca da parte aérea e de raiz foi determinada após o nono dia da germinação, em balança de precisão de 0,0001 g. Após pesagem da massa de matéria fresca, as plântulas foram acondicionadas em sacolas de papel tipo kraft, mantidas em estufa a $80{ }^{\circ} \mathrm{C}$, por 72 horas para determinação da matéria seca e 
os resultados obtidos após pesagem expressos em gramas. A razão raiz/parte aérea foi obtida com os valores das massas de matéria seca da parte aérea e raiz.

\section{RESULTADOS E DISCUSSÃO}

O grau de umidade média obtida nas sementes de feijão foi de $13 \%$, a qual se encontrou dentro dos limites aceitáveis para o armazenamento seguro, de acordo com Marcos Filho (1999), resultado de suma importância considerando-se que a uniformidade da umidade das sementes é
Os dados foram submetidos à análise de variância e as médias dos tratamentos comparadas pelo teste Tukey, em nível de $5 \%$ de probabilidade de erro, pelo software Sisvar (FERREIRA, 2011).

imprescindível para a padronização das avaliações e obtenção de resultados consistentes. As sementes de feijão apresentaram, em média, comprimento, largura e espessura respectivamente, 11,36, 10,06 e 4,90 mm com baixo erro-padrão da média (Tabela 2).

Tabela 2. Biometria e massa média de sementes de feijão cv. Serrano.

\begin{tabular}{ccccc}
\hline & $\mathrm{C}(\mathrm{mm})$ & $\mathrm{L}(\mathrm{mm})$ & $\mathrm{E}(\mathrm{mm})$ & $\mathrm{M} 1000(\mathrm{~g})$ \\
\hline Mínimo & 8,21 & 8,88 & 3,94 & \\
Máximo & 15,04 & 11,20 & 6,79 & \\
Média & $11,36 \pm 0,3$ & $10,06 \pm 0,1$ & $4,90 \pm 0,1$ & 380,20 \\
\hline C: comprimento; L: largura; E: espessura; M1000: peso de & 1000 sementes. \pm erro padrão da \\
média.
\end{tabular}

Segundo Gaspar e Nakagawa (2002), o tamanho da semente é um dos fatores que podem influenciar a sua germinação e o seu vigor, de modo que as maiores potencialmente apresentam maior poder germinativo e vigor em relação às menores. De Pádua et al. (2010) trabalhando com soja, verificaram que sementes maiores (peneira 7,0 $\mathrm{mm}$ ) apresentaram maiores porcentagens de germinação e de vigor. Já sementes menores (peneira 4,0 $\mathrm{mm}$ ) produziram plantas com menor altura e produtividade na colheita. Marcos Filho et al. (1987) relatam o peso e o tamanho da semente como um teste físico para avaliar indiretamente o vigor do lote de sementes.

Resultados semelhantes a esses foram encontrados por Botelho et al.
(2010) trabalhando com feijão, o qual a maior largura (peneira redonda acima de 6 $\mathrm{mm}$ ) apresentou melhor qualidade fisiológica, mostrando que as sementes analisadas nesse estudo apresentavam-se vigorosas, já que, segundo Carvalho e Nakagawa (2012) sementes maiores e de maior densidade possuem, normalmente, embriões bem formados e com maiores quantidades de reservas.

Quanto à porcentagem de germinação, verifica-se que todos os tratamentos não diferiram estatisticamente entre si (Tabela 3 ), porém estiveram acima do valor mínimo estipulado para a comercialização de sementes de feijão, que é de $80 \%$ (BRASIL, 2005), mostrando que as sementes apresentaram-se adequadas para sua utilização. 
Tabela 3. Germinação (G), primeira contagem de germinação (PC), e índice de velocidade de germinação (IVG) em sementes de feijão cv. Serrano, submetidas a águas residuárias.

\begin{tabular}{cccc}
\hline Tratamentos & G $(\%)$ & PC $(\%)$ & IVG \\
\hline T1 & $94 \pm 0,6 \mathrm{a}$ & $90 \pm 1,0 \mathrm{a}$ & $6,60 \pm 0,1 \mathrm{~b}$ \\
T2 & $97 \pm 0,4 \mathrm{a}$ & $95 \pm 0,4 \mathrm{a}$ & $7,64 \pm 0,2 \mathrm{a}$ \\
T3 & $95 \pm 0,6 \mathrm{a}$ & $92 \pm 0,9 \mathrm{a}$ & $7,33 \pm 0,1 \mathrm{ab}$ \\
T4 & $94 \pm 0,5 \mathrm{a}$ & $95 \pm 0,4 \mathrm{a}$ & $7,63 \pm 0,1 \mathrm{a}$ \\
T5 & $92 \pm 0,5 \mathrm{a}$ & $91 \pm 0,4 \mathrm{a}$ & $7,54 \pm 0,1 \mathrm{a}$ \\
T6 & $97 \pm 0,4 \mathrm{a}$ & $93 \pm 1,1 \mathrm{a}$ & $7,55 \pm 0,1 \mathrm{a}$ \\
\hline CV(\%) & 4,7 & 6,9 & 4,8 \\
\hline
\end{tabular}

Médias seguidas de mesma letra, minúscula na coluna, não diferem entre si pelo teste Tukey, a $5 \%$ de probabilidade. $\mathrm{CV}(\%)$ - Coeficiente de variação.

As sementes com os diferentes tratamentos foram avaliadas pelo teste de vigor - primeira contagem (PC), não havendo diferença estatística entre eles (Tabela 3). Assim os tratamentos não beneficiaram e nem prejudicaram a germinação e o vigor (PC). Já para o índice de velocidade de germinação (IVG) houve diferenças estatísticas a qual a testemunha (sem embebição) diferiu dos demais, exceto para o tratamento com água de suinocultura por $1 \mathrm{~h}$. Os demais tratamentos mostraram-se estatisticamente iguais (Tabela 3).

Avaliando IVG e a germinação de meloeiro irrigado com água de abastecimento combinada com água residuária de origem doméstica tratada, Sampaio et al. (2011) não observaram diferença estatística entre os tratamentos estudados em relação água de abastecimento, resultado semelhantes ao encontrados nesse trabalho. Esses mesmos autores obtiveram coeficientes de variação de 17,51 e $31,56 \%$ para germinação e IVG respectivamente, valores superiores aos encontrados nesse trabalho (4,7 e 4,8\% respectivamente), denotando variabilidade baixa, o que conforme classificação de Pimentel-Gomes (2009) indica homogeneidade nos dados.

Lacerda et al. (2011) estudando no campo a influência da irrigação com águas residuárias oriundas de lagoa de estabilização de tratamento de esgoto doméstico e da piscicultura, obtiveram com feijão-de-porco resultados de germinação de $86,6 \%$ para ambas águas residuárias, que diferiram para a água de abastecimento com $66,6 \%$ de germinação, resultados diferentes do presente trabalho. Esses mesmo autores verificaram que o IVG apresentou-se maior para água residuária de esgoto doméstico, diferindo estatisticamente para água de abastecimento.

Do ponto de vista nutricional, os nutrientes presentes na água de reúso, além da grande quantidade de matéria orgânica normalmente presente nesse tipo de água, aliada às concentrações superiores $\mathrm{e}$ disponibilidades dos nutrientes $\mathrm{Ca}, \mathrm{Fe}, \mathrm{K}$, $\mathrm{Mg}, \mathrm{Mn}, \mathrm{P}$ e $\mathrm{S}$, podem influenciar a formação do embrião dos cotilédones resultados eficazes sobre o vigor e a qualidade fisiológica (TEIXEIRA et al., 2005). O Cálcio, por exemplo, é um elemento constituinte da estrutura vegetal com importantes funções fisiológicas no metabolismo, o qual neutralizando ácidos orgânicos e ativando algumas enzimas, como a fosfatase, favorece o poder germinativo das sementes (EMBRAPA, 2006).

Pode-se observar que os tratamentos com água residuária resultaram em menor tempo e frequência de germinação (Fr \%) de sementes de feijão da cv. Serrano (Figura 1). O tratamento sem embebição (T1), embebição com água (T2) e água de 
suinocultura por $1 \mathrm{~h}$ (T3) promoveram comportamento semelhante em relação ao tempo $(4,0 ; 4,05 ; 4,08$ dias $)$. Já os tratamentos T4, T5 e T6 foram semelhantes entre si $(3,98 ; 3,90 ; 3,98$ dias $)$, respectivamente. Para todos os tratamentos o pico máximo ocorreu no terceiro dia, sendo que o T1 apresentou o menor pico de frequência.
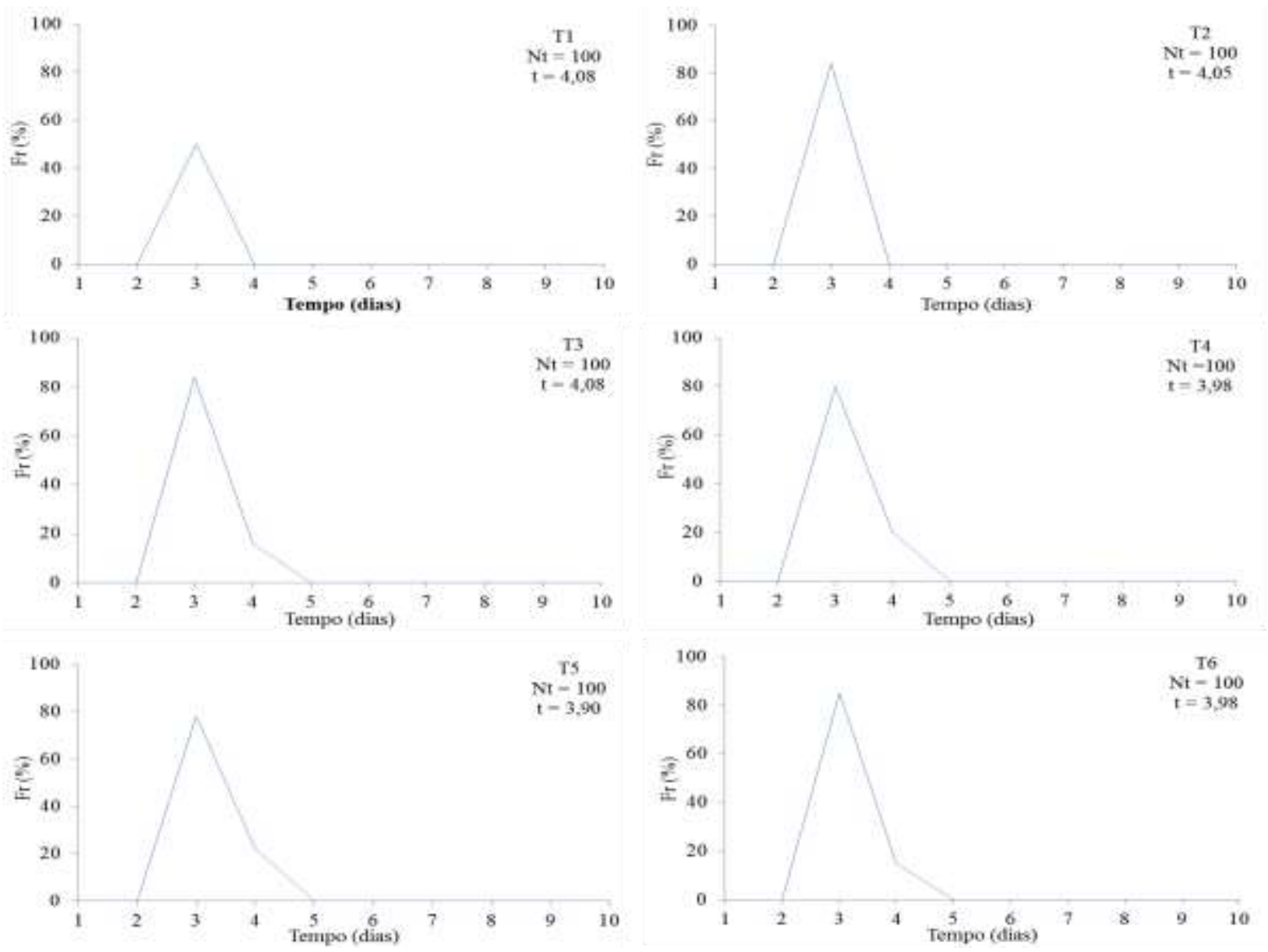

Figura 1. Frequência relativa de germinação - Fr $(\%)$ de sementes de feijão cv. Serrano, submetidas a diferentes águas residuárias. $\mathrm{Nt}=$ porcentagem de germinação, $\mathrm{t}=$ tempo de germinação em dias.

O comprimento da parte aérea (CPA) diferiu estatisticamente em função dos tratamentos em que as sementes foram embebidas, em soro de leite (10\%) por $2 \mathrm{~h}$ (T6) e água residuária da suinocultura por $1 \mathrm{~h}$ (T3). O CPA do T6 mediu 30,0 cm e, do T3 21,7 cm (Tabela 4). Observa-se também que o tratamento com água residuária onde as sementes foram embebidas por maior tempo (T5), proporcionaram CPA maior em relação a T3. Para a avaliação do CR os tratamentos com sementes embebidas em soro de leite
(10\%) por $1 \mathrm{~h}$ (T4) e água residuária da suinocultura por $2 \mathrm{~h}$ (T5), apresentaram diferença estatística para o comprimento de raiz, com 13,9 e 10,5 cm respectivamente, sendo que os demais tratamentos não diferiram entre si. A massa de matéria fresca da raiz (MFR) apresentou diferença entre os tratamentos T6 $(2,7 \mathrm{~g})$ e T1 $(1,7 \mathrm{~g})$, não confirmando os resultados do comprimento das raízes, apenas numericamente T5 foi menor que os demais (exceto T1). 
Tabela 2. Comprimento da parte aérea (CPA), comprimento da raiz (CR), massa de matéria fresca da parte aérea (MFPA), massa de matéria fresca da raiz (MFR), massa de matéria seca da parte aérea (MSPA), massa de matéria seca da raiz (MSR) e razão raiz/parte aérea (R/PA) de feijão cv. Serrano, submetido a águas residuárias.

\begin{tabular}{cccccccc}
\hline Tratamentos & $\begin{array}{c}\text { CPA } \\
(\mathrm{cm})\end{array}$ & $\begin{array}{c}\text { CR } \\
(\mathrm{cm})\end{array}$ & $\begin{array}{c}\text { MFPA } \\
(\mathrm{g})\end{array}$ & $\begin{array}{c}\text { MFR } \\
(\mathrm{g})\end{array}$ & $\begin{array}{c}\text { MSPA } \\
(\mathrm{g})\end{array}$ & $\begin{array}{c}\text { MSR } \\
(\mathrm{g})\end{array}$ & R/PA \\
\hline T1 & $23,4 \mathrm{ab}$ & $12,9 \mathrm{ab}$ & $11,5 \mathrm{a}$ & $1,7 \mathrm{~b}$ & $0,73 \mathrm{a}$ & $0,12 \mathrm{a}$ & $0,16 \mathrm{a}$ \\
T2 & $26,3 \mathrm{ab}$ & $12,2 \mathrm{ab}$ & $13,3 \mathrm{a}$ & $2,1 \mathrm{ab}$ & $0,86 \mathrm{a}$ & $0,13 \mathrm{a}$ & $0,15 \mathrm{a}$ \\
T3 & $21,7 \mathrm{~b}$ & $11,0 \mathrm{ab}$ & $11,4 \mathrm{a}$ & $2,2 \mathrm{ab}$ & $0,75 \mathrm{a}$ & $0,09 \mathrm{a}$ & $0,14 \mathrm{a}$ \\
T4 & $29,8 \mathrm{ab}$ & $13,9 \mathrm{a}$ & $12,2 \mathrm{a}$ & $2,6 \mathrm{ab}$ & $0,93 \mathrm{a}$ & $0,16 \mathrm{a}$ & $0,17 \mathrm{a}$ \\
T5 & $23,3 \mathrm{ab}$ & $10,5 \mathrm{~b}$ & $12,2 \mathrm{a}$ & $2,0 \mathrm{ab}$ & $0,85 \mathrm{a}$ & $0,11 \mathrm{a}$ & $0,13 \mathrm{a}$ \\
T6 & $30,0 \mathrm{a}$ & $11,6 \mathrm{ab}$ & $12,6 \mathrm{a}$ & $2,7 \mathrm{a}$ & $0,86 \mathrm{a}$ & $0,12 \mathrm{a}$ & $0,14 \mathrm{a}$ \\
\hline $\mathrm{CV}(\%)$ & 14,0 & 11,4 & 18,5 & 19,9 & 37,31 & 19,73 & 31,57 \\
\hline
\end{tabular}

Médias seguidas de mesma letra, minúscula na coluna, não diferem entre si pelo teste Tukey, a $5 \%$ de probabilidade. $\mathrm{CV}(\%)$ - Coeficiente de variação.

A massa de matéria fresca da parte aérea (MFPA), massa de matéria seca da parte aérea (MSPA), massa de matéria seca da parte aérea (MSPA), massa de matéria seca da raiz (MSR) e razão raiz/parte aérea (R/PA), não apresentaram diferença estatística entre os tratamentos (Tabela 4). Mas T5 foi que apresentou menor índice, em relação aos demais. Estes resultados são semelhantes aos encontrados por Sampaio et al. (2011) em que não verificaram diferença estatística para massa de matéria seca da parte área e radicular do meloeiro 'Amarelo Ouro' irrigado com diferentes concentrações de água residuária em casa de vegetação.

Resultados diferentes foram encontrados por Rebouças et al. (2010), trabalhando com feijão-caupi irrigado com água residuária de esgoto doméstico tratado, estes pesquisadores também, observaram efeito positivo para a fitomassa total, em que as plantas irrigadas apenas

\section{CONCLUSÃO}

A água residuária da suinocultura e o soro de leite $(10 \%)$ foram eficientes na germinação de sementes de feijão cv.

\section{REFERÊNCIAS}

BARBOSA, L. O.; LIMA, R.; PAULA, A. C.; NASCIMENTO, J. F.; MARINI, F. S.; MELO, R. S. Efeito de concentrações de com efluentes domésticos aumentaram a produção de matéria seca total em $117,07 \%$, evidenciando que a quantidade de nitrogênio existente na água residuária supriu suficientemente as plantas, elevando a produção de fitomassa e demais variáveis.

O tratamento com soro de leite $(10 \%)$ por $1 \mathrm{~h}$ apesar de estatisticamente igual aos demais tratamentos, em relação às variáveis, comprimento da raiz, massa de matéria seca da parte aérea, massa de matéria seca da raiz e razão raiz/parte aérea, apresentou os maiores valores, fato que pode ser explicado pela maior quantidade de nutrientes, principalmente potássio e fósforo nesse efluente conforme Tabela 1. Segundo Nunes et al. (2013) depois do nitrogênio, o fósforo é o principal elemento limitante do crescimento dos vegetais, já o potássio tem sua importância na regulação osmótica das células vegetais.

Serrano, não influenciando a qualidade fisiológica, se tornando alternativas para $\mathrm{o}$ reuso.

urina de vaca no tratamento de sementes de Feijão "Carioca" (Phaseolus vulgaris L.). Cadernos de Agroecologia, v. 8(2): 1-5, 
2013.

BOTELHO, F. J. E.; GUIMARÃES, R. M.; OLIVEIRA, J. A.; EVANGELISTA, J. R. E.; ELOI, T. A.; BALIZA, D. P. Desempenho fisiológico de sementes de feijão colhidas em diferentes períodos do desenvolvimento.

Ciência

Agrotecnologia, v. 34(4): 900-907, 2010.

BRASIL. Ministério da Agricultura, Pecuária e Abastecimento. Padrões para produção e comercialização de sementes de feijão. Instrução normativa $\mathrm{n}^{\circ} 25$, de 20 de dezembro de 2005. Diário Oficial da União, Brasília, DF, 20 dez. 2005. Seção 1, n. $243,18 p$.

BRASIL. Ministério da Agricultura, Pecuária e Abastecimento. Regras para análise de sementes. Ministério da Agricultura, Pecuária e Abastecimento. Secretaria de Defesa Agropecuária. Brasília, DF: Mapa/ACS, 2009. 395p.

CARVALHO, J. J.; SAAD, J. C. C.; BASTOS, A. V. S.; NAVES, S. S.; SOARES, A. L.; VIDAL, V. M. Teor e acúmulo de nutrientes em grãos de feijão comum em semeadura direta, sob déficit hídrico. Irriga, Edição Especial (1): 104117, 2014.

CARVALHO, N. M.; NAKAGAWA, J. Sementes: ciência, tecnologia e produção. 4 ed. Jaboticabal: FUNEP, 2012. 588 p.

DE PÁDUA, G. P.; ZITO, R. K.; ARANTES, N. E.; NETO, J. B. F. Influência do tamanho da semente na qualidade fisiológica e na produtividade da cultura da soja. Revista Brasileira de Sementes, v. 32(3): 9-16, 2010.

DIAS, D. C. F. S.; BHERING, M. C.; TOKUHISA, D.; HILTS, P. C. Teste de condutividade elétrica para avaliação do vigor em sementes de cebola. Revista Brasileira de Sementes, v. 28(1): 154162, 2006.

EMBRAPA - Empresa Brasileira de Pesquisa agropecuária. Mandioca e fruticultura tropical. Circular Técnica. Cruz das Almas: EMBRAPA, 2006, 8p.
FERREIRA， D.F. Sisvar: a computer statistical analysis system. Ciência e Agrotecnologia, v. 35(6): 1039-1042, 2011.

GASPAR, C. M.; NAKAGAWA, J. Influência do tamanho na germinação e no vigor de sementes de milheto (Pennisetum americanum (L.) Leeke). Revista Brasileira de Sementes, v. 24(1): 339344, 2002.

LABOURIAU, L. G. A germinação das sementes. Washington: Secretaria da OEA, 1983. 173 p.

LACERDA, P. M.; RODRIGUES, R. F.; JÚNIOR, H. A. N.; MALAFAIA, G.; RODRIGUES, A. S. L. Influência da irrigação com águas residuárias no desenvolvimento de feijão-de-porco (Canavalia ensiformis). Revista Acadêmica Ciência Agrária e Ambiental, v. 9(2): 159-168, 2011.

MARCOS FILHO, J. Fisiologia de sementes de plantas cultivadas. Piracicaba: FEALQ, 2005. 495 p.

MARCOS FILHO, J. Teste de Envelhecimento Acelerado. In. KRYZANOWSKI, F.C.; VIEIRA, R.D.; FRANÇA NETO, J. de B. (Ed.) Vigor de sementes: conceitos e testes. Londrina: ABRATES, 1999, p.1-24.

MARCOS FILHO, J.; CICERO, S. M.; SILVA, W. R. Avaliação da qualidade das sementes. Piracicaba: FEALQ, 1987, $230 \mathrm{p}$.

MENESES, J. A. G.; SANTOS, V. S.; MENEZES, A. R. V.; ALVES, F. K.; PEREIRA, J. A. Produtividade do feijão caupi (Vigna unguiculata L.walp) utilizando cinzas de bagaço da cana-deaçúcar e esgoto tratado. Revista Verde de Agroecologia e Desenvolvimento Sustentável, v. 9(1): 08-12, 2014.

NAKAGAWA, J. Testes de vigor baseados na avaliação de plântulas. In: VIEIRA, R.D. CARVALHO, N.M. (Orgs). Testes 
de vigor em sementes. Jaboticabal: FUNEP, 1994. p.49-85.

NUNES, E. N.; FERNANDES, Y. T. D.; MONTENEGRO, I. N. A.; ALVES, C. A. B.; SOUTO, J. S. Eficiência da translocação de nutrientes em plantas. Revista Verde de Agroecologia e Desenvolvimento Sustentável, v. 8(5): 90-95, 2013.

PIMENTEL-GOMES, F. Curso de estatística experimental. 15 ed. Piracicaba: FEALQ, 2009, 451p.

REBOUÇAS, J. R. L.; DIAS, N. S.; GONZAGA, M. I. S.; GHEYI, H. R.; NETO, O. N. S. Crescimento do feijãocaupi irrigado com água residuária de esgoto doméstico tratado. Revista Caatinga, v. 23(1): 97-102, 2010.

SAMPAIO, P. R. F.; ALMEIDA, J. P. N.; MOTA, A. F.; COSTA, L. R.; GURGEL, M. T. Utilização de águas residuárias na germinação e Desenvolvimento inicial de mudas de meloeiro 'Amarelo Ouro'. Revista Verde de Agroecologia e Desenvolvimento Sustentável, v. 6(1): 179-187, 2011.

SILVA, E. A.; RAMOS, J. D.; SILVA, F. O. R.; SOARES, F. M.; SANTOS, V. A.; FERREIRA, E. A. Adição de água residuária de laticínio em substrato para produção de mudas de maracujazeiro 'amarelo'. Revista Agrarian, v. 7(23): 4959, 2014.

TEIXEIRA, I. R.; BORÉM, A.; ARAÚJO, G. A. A.; ANDRADE, M. J. B. Teores de nutrientes e qualidade fisiológica de sementes de feijão em resposta à adubação foliar com manganês e zinco. Bragantia, v.64(1): 83-88, 2005. 